\title{
Sağlık Hizmetlerini Yönetmek Neden Zordur?: Teorik Tartışmalar
}

\section{Why Is It So Hard To Manage Healthcare?: Theoretical Discussions}

\author{
Mehtap Çakmak Barsbay ${ }^{a^{*}}$ \\ ${ }^{a}$ Dr. Öğr. Üyesi, Karamanoğlu Mehmetbey Üniversitesi, Sağlık Bilimleri Fakültesi, Sağlık Yönetimi Bölümü, Karaman/Türkiye. \\ ORCID: 0000-0001-7609-6254
}

\section{MAKALE BILGİSİ}

\section{Makale Geçmişi:}

Başvuru tarihi: 20 Eylül 2018

Düzeltme tarihi: 12 Aralık 2018

Kabul tarihi: 25 Aralık 2018

Anahtar Kelimeler:

Sağlık Hizmeti

Sağlık Kurumları

Sağlık Yönetimi

\section{ARTICLE INFO}

\section{Article history:}

Received 20 September 2018

Received in revised form 12 December 2018

Accepted 25 December 2018

\section{Keywords:}

Health Services

Healthcare Organizations

Health Administration
ÖZ

Kamuda sağlık hizmeti sunan kuruluşlar, diğer kamu kuruluşlarından farklı olarak kendine münhasır, spesifik özelliklere sahiptir. Sağlık hizmeti sunan kuruluşlar, farklı mesleklerden uzmanların işgücünü, tıp teknolojisini ve basit sarf malzemeden robotik özellikli tıbbi cihazlara kadar geniş perspektifte maddi kaynağı kullanırlar. Ayrıca, yoğun emek, aşırı uzmanlaşma ve sermaye yoğun teknolojinin kullanılması sağlık kurumlarına özgüdür. Sağlık hizmetleri sunumunda disiplinler arası takım çalışması ihtiyacı gittikçe yaygınlaşmakta, örgütsel ve profesyonel sınırların katkısıyla geniş çapta zorluklar ortaya çıkmaktadır. Bu çalışmanın amacı, sağlık kurumlarının kültürel, işlevsel ve örgütsel özellikleri bağlamında diğer örgüt türlerinden farklılaşma noktalarını tartışmaktır. Örgütü yapısal, kültürel ve işlevsel bakımdan ele alan teori ve yaklaşımların, bazı sınırlılıklarına rağmen sağlık kurumları yönetiminde kullanımının faydalı olacağı sonucuna varılmıştır.

\section{A B S T R A C T}

Public health service organizations have distinctive and unique characteristics. They use a wide range of resources, which mainly consist of professional healthcare workers, medical technology, basic consumables, and robotic medical devices. Further, continued high labor intensity, high specialization and capital-intensive technology are specific to healthcare organizations. Moreover, need for interdisciplinary team work is increasingly prevalent, and there has been a great deal of challenge supported by organizational and professional boundaries. It is the purpose of the study to discuss the differentiation points of healthcare services and organizations in terms of cultural, functional and organizational characteristics. Although there are some limitations of theoretical approaches which places the most emphasis on the structural, cultural and functional characteristics of the organization, they could be involved in the management of healthcare organizations.

\section{Giriş}

Sağlık hizmeti sunan örgütler, eski devirlerdeki şifa merkezleri olmaktan çıkıp karmaşık organizasyonlara evrilmiştir (Bate, 2000). Bu örgütler, hizmeti sunabilmek için farklı mesleklerden uzmanların işgücünü, güncel tıp teknolojisini, basit sarf malzemeden nano ve robotik özellikli tıbbi cihazlara kadar geniş perspektifte maddi kaynağı kullanmaktadır. Bu nedenle, sağlık harcamaları artış göstermektedir (Cutler ve McCellan, 2001). Türkiye'de sağlık hizmetlerine toplam ülke bütçesinden ayrılan pay, yaklaşık $\% 5$ dolayındadır. Sağlık istatistiklerine göre Türkiye'de sağlık hizmetleri, 2018 yılı itibariyle toplam 581.698 sağlık insan gücü tarafindan sunulmakta olup bu sayı, sağlık sektöründeki çalışanların 2/3'ünü oluşturmaktadır. Sağlık insan gücünün 1/3'ünü ebe ve hemşireler; 1/4'ünü ise hekimler oluşturmaktadır. Sağlık kurumlarında farklı meslekteki sağlık çalışanlarının, ekip halinde ve disiplinler arası uyum içinde hizmet sunmaları gerekir (Leggat, 2007). Sağlık örgütlerinin sayısı, genel bir eğilim olarak y1llar bazında artmaktadır. Türkiye'de 2017 verilerine göre 571'i özel hastane olmak üzere toplam 1518 hastane, 25.198 aile hekimliği birimi, 5.320 sağlık evi, 2.618 112 acil yardım istasyonu faaliyet göstermektedir. Sağlık örgütlerinin sayısındaki artışa bağlı olarak sağlık hizmetlerine erişim olanağ 1 artmaktadır. Kişi başına sağlık hizmetlerine müracaat, son 15 yılda yaklaşık üç katına yükselerek birinci

* Sorumlu yazar/Corresponding author.

e-posta: mehtapcakmak@gmail.com 
basamak sağlık kurumlarına yıllık 2,8; ikinci ve üçüncü basamak sağlık kurumlarına ise 6 kez gerçekleşmiştir. Toplam müracaatların yaklaşık 1/10'i özel sektör sağlık kuruluşlarına yapılmıştır (Sağlık Bakanlığı, 2018).

Kamuda sağlık hizmeti sunan kuruluşlar, diğer kamu kuruluşlarından farklı olarak kendine münhasır, spesifik özelliklere sahiptir (Kavuncubaşı, 2000). Yoğun emek, aşırı uzmanlaşma ve sermaye yoğun teknolojinin kullanılması sağlık kurumlarına özgüdür. Sağlık hizmetleri sunumunda disiplinler arası takım çalışması ihtiyacı gittikçe yaygınlaşmakta, örgütsel ve profesyonel sınırların katkısıyla geniş çapta zorluklar ortaya çıkmaktadır (Raelin, 1999; Dickinson ve Ham, 2008; Leggat, 2007). Bu nedenle sağlık örgütlerini yönetmenin bazı yönlerden zorluklarının bulunduğu ileri sürülebilir. Bu çalışmada, sağlık kurumlarının diğer örgüt türlerinden farklılaşma noktaları kültürel, işlevsel ve örgütsel özellikleri bağlamında tartışılmaktadır.

\section{Sağlık Kurumlarının Kültürel Özelliklerinin Neden Olduğu Zorluklar}

Sağlık örgütleri, farklı mesleğe sahip uzmanların ekip halinde çalışmalarının ve yüksek düzeyde koordinasyonun gerektiği kurumlardır. Her ne kadar maliyet artırıcı bir unsur olarak ele alınsa da değişimin ve yenilikçi uygulamaların izlenerek hizmet kalitesinin ve sağlı meslek mensuplarının performansının artırılması gereği ortaya çıkmaktadır (Goes ve Park, 1997).

Farklı meslek mensupları arasında özellikle doktorlar, klinik bakım ekibinin önemli bir bileşeni olup diğer personele kıyasla daha yüksek nüfuza ve güce sahiptir (Degeling vd., 2003). Bu nedenle, hekimlerin sahip olduğu mesleki özerklik (Kılıç vd., 2008), klinik süreçlerin yönetimini (Şahin, 1999) ve yönetsel müdahaleleri zorlaştırmakta ve kurumlarda çatışma ortamını (Dickinson ve Ham, 2008) yaratabilmektedir. S1klıkla gözlemlenen çatışma türleri, hiyerarşinin ve prosedürlerin fazlalığ 1 , iş stresi, yöneticilerin risk almaktan imtina etmeleri, çalışanların yeterince değer görmemesi, yöneticilerin sorun çözememesi, her mesleğin beklentilerinde farklılık olması ve kurumsal kültürün oluşmaması şeklinde sınıflandırılmaktadır (Gemlik vd., 2015). Çatışmalar çoğunlukla, yöneticinin örgütsel bağlılığına dayanan kurumsal kültürle, profesyonelleri sosyalleştirmeye dayanan profesyonel kültür arasındaki farklılıktan kaynaklanmaktadır (Raelin, 1999, 19).

Sağlık kurumlarında, sağlık profesyonelleri ve yöneticiler, profesyonel kültür ve görev kültürü olmak üzere örgütün iki farklı kültürünü oluşturmaktadır (Thorne, 2002). Sağlık profesyonelleri faaliyetlerini uzmanlık bilgisini, yöneticiler ise makamlarını kullanarak sürdürmektedir. Bu durumda bilgi, üstün konuma yerleşerek güce sahip olmaya aracılık etmektedir (Galbraith, 1967). Sağlık kurumlarında güç, bilgi ve beceriye sahip olma ile ilişkilendirilmektedir. Bu nedenle, sağlık örgütlerinde yöneticilik yapmak isteyenlerin gücü elde edebilmeleri için, yönetim eğitimi alarak temel becerilerini geliştirmeleri gerekmektedir (Santos ve Eisenhardt, 2005).

Sağlık kurumlarında, farklı mesleklerin görev yapması nedeniyle mesleki kültürler arasında etkileşim bulunmaktadır (Raelin, 1999). Sağlık örgütleri, zayıf bağlarla birbirinden ayrılmış ve silolarda, farklı alt kültürlerin bir arada bulunmaya devam ettiği (Bate, 2000), birbirinden ayrı alt organizasyonlar topluluğudur. Literatürde sağlık kurumlarında hâkim olan kültürel yapıları inceleyen çalışmalar bulunmaktadır. Sağlık kurumlarında farklı departmanlarda çalışanların, rekabet gruplarına evrildiği ve birbirinden farklı kültürel özelliklere sahip olduğu iddia edilmektedir (Raelin, 1999). Her grup meşruiyet bakımından kendini diğerlerinden farklılaştırmaktadır (Kouzes ve Mico, 1979).

Sağlık kurumlarında siyasi, yönetsel ve hizmet olmak üzere üç farklı alan bulunmaktadır. Siyasi alandakiler, politika geliştirerek seçilmişlerin talep ve beklentilerini karşılamaktadır. Yönetsel alan, hesap verebilirlik doğrultusunda kaynakları etkin ve verimli kullanarak örgütsel amaçlara ulaşmada rol almaktadır. Hizmet alanı ise uzmanlık bilgisini kullanarak meslek etiği ve özerklik doğrultusunda en iyi hizmetin üretilmesini ve sunulmasını sağlamaktadır. Sayılan üç farklı alan, sınırları dahilinde hizmet ederek meşruiyeti tesis edecek mekanizmalar geliştirme eğilimindedir (Kouzes ve Mico, 1979). Dahası, her alanın ayrı gündeminin olması, gruplar ve alanlar arası bağlantısızlığı ve iletişimsizliği ortaya çıkarmaktadır (Edmonstone, 1986). Bu durumda, alanlar arasında çıkar çatışmaları ortaya çıkabilmektedir (Dickinson ve Ham, 2008). Artan çatışmaların çözülememesi durumunda, kurumsal vizyon oluşması ve örgütsel amaçların yerine getirilmesi sekteye uğrayabilecektir.

Sağlık kurumlarında alan farklılığına yönelik örnekler bulunmaktadır. Yönetim pozisyonuna gelen hekimler, alan değiştirmeleri nedeniyle sıklıkla hizmet alanından izole edilmekte ve meslektaşlarınca bazı engellemelere maruz birakılmaktadır (Loh, 2013; Edmonstone, 1986).

Sağlık kurumlarında farklı kültürlerin bulunması nedeniyle karşılaşılan sorunların ve güçlüklerin aşılmasında takım çalışması ve iş birliği (Leggat, 2007) stratejisinin önemine dikkat çekilmektedir. Yöneticinin kontrol ve profesyonellerin özerklik ihtiyacı yüzünden ortaya çıkan potansiyel çatışmayı yatıştırmada önerilen diğer bir strateji ise profesyonel yönetici mekanizmasının kullanılmasıdır (Raelin, 1999). Bu mekanizma, yönetim ve profesyoneller arasındaki etkileşimli dinamiklerden ortaya çıkan kooptasyonun (Pfeffer, 1973) pratiğe yansıması olarak değerlendirilebilir.

Bazı çalışmalarda takım çalışmasından ziyade profesyonellerin ve yöneticilerin bireysel inisiyatif kullanma kapasitelerinin güçlendirilmesine (Raelin, 1999) artan oranda vurgu yapılıyor olsa da sağlık hizmetleri sunumunda görev alan meslek mensuplarına, iş birliğine ve takım çalışmasına yönelik eğitim verilmesi faydalı olacaktır.

\section{Sağlık Hizmetlerinin İşlevsel Özelliklerinin Neden Olduğu Zorluklar}

Genel olarak hastalıklardan korunma, hastalıkların önlenmesi ve hastalıkların uygun şekilde tedavi edilmesi bağlamında sağlık kavramı tanımlanmaktadır (Fişek, 1985). Dünya Sağlık Örgütü, sağlık hizmetleri sistemini, sağlık kurumlarında, farklı meslek grubu üyesi sağlık personelinden yararlanarak toplumun gereksinme ve istemlerine göre değişen amaçları gerçekleştirmek, böylece bireylerin ve toplumun sağlık bakımını her türlü koruyucu ve tedavi edici etkinliklerle sağlamak üzere ülke çapında örgütlenmiş kalıcı bir sistem olarak tanımlamış ve sağlık hizmetlerini koruyucu, tedavi edici ve rehabilite edici olmak üzere üç grupta incelemiştir (WHO, 2011; Çakmak, 2016). Sağlık hizmetlerinin diğer hizmetlerden farklı niteliklerine, literatürde sıklıkla benzer şekilde vurgu yapıldığı görülmektedir. Sağlık hizmetleri, hizmet sektörünün genel niteliklerine sahip olmakla beraber 
spesifik özelliklere sahiptir (Kavuncubaşı, 2000). Ayrıca, tıbbi hizmetlerin çekirdekte yer aldığı bir hizmet alanı olarak bazı özelliklerle karakterize bir yapı sergilemektedir (Bannerman vd., 1983). Sağlık hizmetleri çoğunlukla, diş denetime tabi olup toplumun özel beklentilerini karşılamak durumunda kalmaktadır (Ginter vd., 2018: 10). Ancak, bu beklentilerin karşılanması, sağlık hizmetinin bazı nitelikleri nedeniyle her zaman mümkün olamayabilmektedir.

Sağlık hizmetlerinde sunulan hizmetin niteliğini, miktarını ve kalitesini belirleyen taraf, hizmeti alan değil, hizmeti sunan hekimlerdir (Taner ve Antony, 2006). Bunun nedeni, hizmetten faydalananların, uzmanlık bilgisi gerektiren sağlık ve tıp konularında yeterli bilgi düzeyinde bulunmaması, diğer bir ifade ile sağlık okuryazarlığı düzeyinin düşük olmasıdır (Akbulut, 2015). Hizmetten yararlananların sahip olduğu bilgi, tedavi sürecine müdahaleyi gerektirebilecek düzeye ulaşmadığından, taraflar arasındaki bilgi seviyesi simetrik görünümde değildir. Diğer yandan, tıbbın mesleki özerliği, hizmetin içeriğine doğrudan müdahaleye ve manipülasyona imkân tanımamaktadır. Ayrıca sağlık hizmetlerine duyulan ihtiyacın zamanlaması kontrol altına alınamamaktadır. Dolayısıyla ertelenemez ve başka bir hizmet, sağlık hizmetini ikame edemez. Fiyatlar düzeyindeki artışa bağlı olarak talebin azalacağı yönündeki genel beklentinin aksine, sağlık hizmetlerinin fiyatındaki artış, talebi büyük ölçüde etkilememektedir (Folland vd., 2007). Hizmet endüstrisi olan sağlık kurumlarında üretim ve tüketim aynı anda gerçekleştiğinden (Özcan, 2013: 25) sunulan hizmet, üretildikten sonra stoklanacak ve piyasaya arzı ileri tarihlere bırakılabilecek nitelikte değildir.

Sağlık örgütlerinde, alanlarında uzmanlaşmış meslek mensupları hizmet vermektedir. Bu nedenle personel giderleri, kurumların toplam giderleri içinde önemli paya sahiptir (Williams vd., 1995). İleri uzmanlık seviyesi, sağlık kurumlarında kullanılan sermaye yoğun teknoloji ile birleştiğinde, sağlık hizmetlerinin arzı pahalı hale gelmektedir. Ayrıca, sağlık profesyonelleri arasında işlevsel bağımlılık yüksektir. Bu nedenle, sağlık kurumlarında farklı meslek gruplarının üyeleri arasında koordinasyon ve iş birliği gerekmektedir (Kavuncubaş1, 2000). Her meslek grubunun mesleki önceliği ve hedefi farklılaştığından, uygun motivasyon araçlarının kullanılması gereği ortaya çıkmaktadır (Leggat, 2007).

Sağlık kurumları, sistem yaklaşımının bir tezahürü olarak alt sistemlerden (Bertalanffy, 1968) oluşan karmaşı örgüt yapısına sahiptir. Ayrıca, sağlık kurumlarında farklı hiyerarşiler bulunmaktadır (Bate, 2000). Şöyle ki, sağlık hizmetini sunan sağlık/tıp mesleği mensupları ve ana hizmetin sunum yeri olan klinik/polikliniklerden sorumlu tıbbi yönetim ile genel ve destek hizmetlerden sorumlu işletme yönetimi eş zamanlı sürdürülmektedir. $\mathrm{Bu}$ sebeple, sağlık kurumları yönetimi, diğer örgüt yapılarının yönetiminden farklı bir yerde durmaktadır. Ayrıca, sağlık kurumlarında gerçekleştirilen faaliyetler, standart özellikte olmayıp değişkenlik gösterebilmektedir. Her ne kadar kanıta dayalı tıp uygulamaları ve klinik uygulama rehberleri yaygınlaşmış olsa da sunulan sağlık hizmetinin standartlaştırılmaması nedeniyle, her hasta için özellikli adımların izlenmesi gerekebilmektedir. Ayrıca sağlık hizmetleri, hatalara karşı duyarlıdır.

Sağlık kurumlarında bireysel ve kurumsal performansın kantitatif ölçümü her zaman kolay değildir. Sağlık hizmetlerinde performans, sağlık statüsünün artırılması genel amacına ulaşmak bakımından araçsal değer taşımasına rağmen amaçsal değer (Sen, 1999) taşıyan bir kavrama büründürülmektedir. Ayrıca, sağlık hizmetinden faydalananların sayısı belirgin değildir. Örneğin aşı uygulamalarında, pozitif dışsallıklar nedeniyle sadece aşı yapılan kişi değil toplum korunmuş olacağından, aşıdan faydalananların sayısı belirsizdir. Sağlık Bakanlığının yayınladığı sağlık istatistiklerine göre, 2002 yılında aşılama hızları \%72 ile \%82 arasında iken 2017 yılında aşılama hızları artarak \%93 ile \%96 seviyesine gelmiştir. Aşı ile önlenebilir bulaşıcı hastalıkların prevelansının azaltılması sonucu toplumun genel sağlık düzeyi iyileşeceğinden, toplumu ilgilendiren hizmet bileşenlerine yönelik performans ölçümü zor olabilmektedir.

Hizmetin kalitesinin sayısallaştırılması da bir başka sorunlu bileşendir. Her ne kadar sağlı hizmetlerinde kalitenin ölçülmesine yönelik olarak Servqual (Parasuraman vd., 1988; Camgöz-Akdağ vd., 2013) ve Servperf (Cronin ve Taylor, 1992) gibi ölçeklerle bilimsel araştırmalar yapılsa da memnuniyet ölçümünde asgari bekleme süresine riayet edilmeden yapılan bu araştırmaların sonuçları sorgulanmaktadır (Fitzpatrick ve Hopkins, 1983). Verimlilik ve performans ölçümlerinde, standardize edilemeyen tedavi seçeneklerinin birbiri cinsinden ifade edilerek analize katılması (Çakmak vd., 2009), verimlilik ve performans ölçümlerinin sonuçlarını tartışmaya açık hale getirmektedir.

Sağlık hizmetleri, teknolojinin gelişmesiyle doğru orantılı olarak değişime uğrayan hasta merkezli bir sektörel yapıda ve çok bileşenli bir model dahilinde sunulmaktadır (Swan, 2009). 10 yıl önce bilim kurgu olarak nitelenen sağlık uygulamaları, sağlık hizmetleri 3.0 gibi yaklaşımlar, teknoloji ile yenilikçi müdahalelerin keşfi ve ulaşılabilir hale gelmesiyle hem hizmet sağlayıcıları hem de ödeme kuruluşlarını dönüşüme uğratmaktadır (Pillay, 2018). Kan şekeri ölçen saat, göz damlası yerine kullanılabilecek lensler, kalp krizini tespit eden telefon uygulamaları gibi akıllı sağlık uygulamaları, üç boyutlu doku ve organların üretilmesi (Medgadget, 2017), enfeksiyöz hastalıklarda, meme kanseri tespitinde, kardiyovasküler hastalıkları tespit etmede binlerce değişkeni bir arada değerlendirme ve anlamlandırma potansiyeline sahip yapay zekanın kullanımı (Pillay, 2018), e-sağlık uygulamaları, girişimsel olmayan retina taraması ile Alzheimer hastalığının erken tanılaması gibi biyoteknoloji uygulamaları ve sağlık bilişimindeki yenilikler, sağlık hizmetlerinde değişim yönetimini zorunlu kılmaktadır. Bu değişimler, hizmetin sunulduğu örgütlerin sınırlarını genişletmektedir.

Diğer yandan, sağlık hizmeti ihtiyacının karşılanmasında uzaktan hizmet alma imkânı ortaya çıkmaktadır. Teknolojik ilerlemeler, çok sayıda, yeni ve güçlü sağlık araçlarının üretilmesini sağladığı için geleneksel sağlık hizmeti sunucularının rollerinde değişikliğe neden olabilmektedir. Örneğin dermatoloji uygulamaları ile etkilenen alanın fotoğrafının çekilip görüntüsünün yüklenmesi ile tanı konulabilmekte ve tedavi sürecine dair izlenecek adımlarla ilgili talimatlar alınabilmektedir (Pillay, 2018).

Gelecek birkaç yılda hastaların, sağlık okuryazarlığının artması ile hizmet talep edenden hizmet üreten rakiplere doğru evrileceği (Zeckhauser ve Sommers, 2013) öngörülmektedir. Bir diğer faktör olarak, bilgi iletişim teknolojilerindeki gelişmelerin sağlık hizmetlerine yansıması ile birlikte karar destek sistemleri, uzaktan sağlık hizmeti sunulması, planlama ve kaynak tahsisinde bilgi işlem ve sayısal teknolojilerin 
kullanımı, sağlık verilerinin yönetimi alanlarında gelişmeler ve yenilikler ortaya çıkmaktadır (Jemal vd., 2015).

Sağlığın işlevsel özelliklerindeki bu değişimler, hizmetin sunulduğu örgüt yapısının yeniden ele alınmasını, koşullara göre tasarımının esnek hale getirilmesini gerekli kılmaktadır. Teknolojik çözümlerin kullanılabilirliğinin artması ve kullanıcılarca hızla benimsenmesi, sağlık insan gücü sayısındaki yetersizlik nedeniyle artan kapasite sorunları, biyomedikal araştırmalardaki ilerlemeler ve bilimsel bilginin artması, sağlık hizmetlerinin sunumu ve organizasyon yönetiminde değişimi tetiklemektedir.

\section{Sağlık Kurumlarının Örgütsel Yapısının Neden Olduğu Zorluklar}

Sağlık kurumlarının tüm organizasyonel birimleri, genellikle anatomik bölümler, organlar, tıbbi teknolojiler veya hastaların yaş grupları temelinde oluşturulmuştur (Montgomery, 1990). Diğer yandan hekim ve hemşireler, aldıkları eğitimin sonucu olarak söz konusu kriterlere göre uzmanlık alanlarına ayrılmaktadır. Uzmanlığa dayalı yapılandırılan sağlık örgütü, literatürde farklı kategoriler dahilinde incelenmektedir. Sağlık kurumlarının örgütsel yapısı işleyen çekirdek, stratejik üst kademe, orta düzey, teknik düzey ve destek düzey olmak üzere beş temel bileşenden oluşmaktadır. Bu modele göre, basit yapılanmalı örgütlerde en önemli bileşen stratejik üst kademe iken, makine bürokrasi örgütlerinde teknik düzey ve profesyonel bürokrasinin hâkim olduğu örgütlerde işleyen çekirdektir (Mintzberg, 1980). Görüldügüü gibi öne çıkan bileşen, örgüt türüne göre farklılaşmaktadır.

Geleneksel basit yapılanmalı örgüt, makine bürokrasisinin egemen olduğu örgüt, profesyonel örgüt, bölümlere ayrılmış/ çeşitlendirilmiş örgüt ve adhokrasi tipi örgüt sınıflaması çerçevesinde sağlık kurumları, profesyonel bürokratik örgüt yapısına sahiptir (Mintzberg, 1980). Bu nedenle sağlık kurumlarında, temel bileşen işleyen çekirdek olup tıp ve sağlık meslek mensuplarından oluşmaktadır. Profesyonel bürokrasiler, makine bürokrasilerinden farklı olarak, çıktılar yerine profesyonellerin becerilerinin standartlaşmış olduğu, mesleki özerkliğin bulunduğu, örgütün yapısal bileşenleri arasında entegrasyonun zayıf olduğu örgütlerdir. Makine bürokrasisi örgütlerde ise katı ve kuralların hâkim olduğu örgüt yapısı, bilgiye dayalı, esnek ve koşullara bağlı bir yapının varlığına çoğunlukla izin vermemektedir. Bu eğilimin karşı tarafında konumlandırılması mümkün olan koşul bağımlılığı kuramına göre, her yerde geçerli olabilecek bir sağlık örgütü yapısı (Olden, 2016), her zaman istendik sonuçları ortaya çıkarmayacağı gibi, ideal örgüt yapısı ve örgüt içi unsurlar yere, zamana ve koşullara göre değişebilecektir.

Sağlık kurumlarında görev yapan tıp ve sağlık meslek mensupları, eğitimleri ve mesleki hedefleri bakımından yöneticilerden farklılık göstermesine rağmen bu ayrım, sağlık kurumlarında görev yapılan departmanlar düzeyinde geçerliliğini yitirebilmektedir. Sağlık kurumlarında işlevsel bölünmeye dayalı departmanlarda sunulan hizmetlerde destek personeli görev yapmaktadır. $\mathrm{Bu}$ bakımdan yönetim fonksiyonlarının yerine getirilmesi sırasında yöneticiler güçlüklerle karşılaşmaktadır. Sağlık hizmeti, ekip çalışmasını gerektirse de mesleki hedeflerin farklılığ 1 örgütsel amaçlara ulaşılmasını sekteye uğratabilmektedir. İlaveten özerklik, sinerjiyi zorlaştırdığı gibi çatışmaya dayalı rekabete neden olabilmektedir (Kılıç vd., 2008). Psikiyatristler ve klinik psikologlar, fizyoterapistler ve fizik tedavi uzmanları arasındaki mesleki çatışma en bilinen örnekleridir (Çakmak, 2016).

Profesyonel ve yönetici ayrımına vurgu yapan "çift başlı ejderha" (Drucker, 1980) metaforu, geleneksel örgüt yapıs1 yerine profesyonel örgüt yapısının varlığına işaret etmektedir. Yönetim ve profesyonel ayrımı, yönetimin profesyonellerin mesleki alanına müdahale etmeleri durumunda belirginleşmekte ve yönetim güçlükleri ortaya çıkarabilmektedir. Bu durumda birbirine yakın düzeyde güç ve otoritenin kullanıldığı örgüt yapılanmaları ön plana çıkmakta ve bunlar, birleşik profesyonel örgütler olarak adlandırılmaktadır (Scott, 1982). Görüldüğü gibi farklı yapısal özelliklere sahip sağlık örgütlerini yönetmenin zorluğunun, aşırı iş bölümüne dayalı uzmanlaşmadan ve profesyonelleşmenin hiyerarşik otoriteyi zayıflatmasından kaynaklandığı söylenebilir. Bu açıdan, sağlık örgütlerinde yönetim, hekimlerin, uzmanların, profesyonellerin, farklı mesleklerin koordinasyonunun sağlanması bakımından önem taşımaktadır. Ayrıca, gittikçe artan sağlık harcamaları baskısı (Embertson, 2006) altında olan yöneticiler, tıbbi süreçlere müdahale edebilmektedir (Mintzberg, 2002). Değinilen yapısal nedenlerle sağlık örgütleri, biçimsel olarak diğer örgüt türlerinde rastlanmayan yönetim zorlukları ile karakterize bir görünüm sergilemektedir.

Geleneksel olarak sağlık kurumları, klinik departmanları (iç hastalıkları, cerrahi vb.) destekleyecek şekilde işlevsel birimler olarak organize edilmektedir (Montgomery, 1990). İşlevsel bölümlenmeye dayalı örgütsel yapının ortaya çıkardığı personelin uzmanlaşması, özellikle hekimlerin lehine olacak şekilde katı bir hiyerarşi ve kararlarda hekim otonomisi ile kendini göstermektedir. $\mathrm{Bu}$ ayırıcı hiyerarşi, hekim yöneticilerin (klinik şefliği gibi) genellikle ve aşırı şekilde otoriter liderlik davranışı göstermelerine neden olmaktadır. Bu nedenle, sağlık kurumlarının bu tür organizasyonel yapıdan kaynaklı olarak işlevsel bölümlere ayrılmış, merkezi, esnek ve etkin olmayan şekilde faaliyet gösterdikleri iddia edilmektedir (Kuntz ve Vera, 2007). Bu nedenle, sağlık kurumları için profesyonel bürokrasinin riskli bir şablon olduğu, bu örgütleri bölümlere ayrılmış adhokrasi şeklinde yapılandırmanın daha uygun olacağı savunulmaktadır (Unger vd., 2000).

Profesyonellerin çoğu organizasyonlarda hizmet sunduğundan, organizasyonlar da yap1 itibariyle uzmanlık özerkliğini ve etik standartları tehdit ettiğinden (Raelin, 1999) dolayı şu soru öne çıkmaktadır. Organik ve esnek yapılı, bir diğer ifadeyle sınırları muğlak örgütler sağlık sektörü için uygun çözüm müdür?

Nüfusun yaşlanması, kronik hastalıkların yaygınlaşması ve ortalama ömrün uzaması gibi toplumsal değişimlerin yanı sıra bilim ve teknolojideki ilerlemeler, merkezi, genel ve tedavi edici bakımdan, dağıtılmış, kişiselleştirilmiş ve önleyici bakıma doğru eksen kaymasını gerektirmekte; aynı zamanda, mümkün hale getirebilmektedir (Romero vd., 2011). Ülkeler, yasal düzenlemeler yoluyla zaman zaman bu organizasyonel yapıyı destekleyecek adımlar atabilmektedir. Hatta, Almanya gibi gelişmiş ülke pratikleri ile Türkiye gibi gelişmekte olan ve Güney Afrika gibi gelişmemiş ülkelerdeki sağlık organizasyonlarının yapılanması benzerlik gösterebilmektedir.

Sağlık kurumlarının, işlevsel bölümlere ayrılmış yapı yerine pazar koşullarının kullanımına imkân verecek, esnek ve etkin yapılar şeklinde modern organizasyonlara dönüştürülmesi stratejisi son yıllarda tartışılmaktadır. Bunlardan biri olan 
modüler sağlık örgütü yapısı, performans üzerindeki olumlu etkileri bağlamında son 10 yılda literatürde yer bulmaktadır. Tanı İlişkili Gruplar (DRG) temelinde, vaka şiddetine göre hastanelerin organizasyonel yapılarının belirlendiği uygulamalar ve ülke örnekleri bulunmaktadır. Benzer şekilde örgüt teorisinde, esnek örgüt yapılarına olan ihtiyacı tanımlayan ve tartışan şebeke/ağbağ örgütler, bilgi ekonomisi/çağ1 örgütleri, adhokratik yapılar, karmaşı/kaotik yapılar literatürde dikkat çeken anahtar kelimeler olarak karşımıza çıkmaktadır. Ayrıca, sistem yapısını alt sistemlere ayırarak alt sistemlerin birbirleriyle daha gevşek ilişkiler sürdüreceği yeni yapılanma önerileri (Şekil 1) ortaya konulmaktadır.

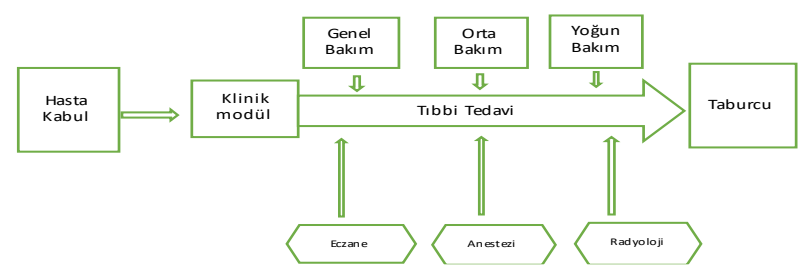

Şekil 1 Bir Sağlık Kurumunda Klinik Modül Yapısı (Kuntz ve Vera, 2007)

Modüler yapılanmanın benimsenmesi durumunda, birimlerin birbirine hizmet vermelerinin karşılı̆̆1 olarak transfer harcamalar1/fiyatlamaları gibi finansal konular ortaya çıkmaktadır. Örneğin ameliyat edilen bir hasta hem cerrahi hem de anestezi hizmeti alacağından hizmeti finanse eden kuruluşlarca yapılan ödemeden elde edilen gelirin, cerrahi ve anestezi hizmetine paylaşımı ve bu iki birimin birbirine verdikleri hizmetin fiyatının belirlenmesi gerekecektir (Kuntz ve Vera, 2010). Bu durumda süreçlere ve süreç adımlarına odaklanarak katma değer oluşturmayan faaliyetlerin elimine edilmesi ve/veya bu faaliyetlere ayırılan sürenin minimum düzeyde tutulması gerekecektir. Bu amaca dayanan yalın yönetim anlayışı 21. yüzyılda sağlık kurumlarında dikkat çekmeye başlamıştır. Ancak çalışmalar, sağlık kurumlarındaki hiyerarşik organizasyonel yapının yalın yönetimi sekteye uğratabileceğini göstermektedir (Leggat vd., 2018). Sağlik örgütlerinde, işlevselliğe dayalı bir yapı yerine, örgütün içinde bulunduğu yasal çevresi, yapının merkezi ya da desantralize olması, yönetim kültürü, izleme ve değerlendirme kriterlerinin niteliği gibi çok bileşenli kriterleri kullanma alternatifi değerlendirilebilir.

\section{Sonuç ve Değerlendirme}

$\mathrm{Bu}$ çalışmada, sağlık kurumlarının kültürel, işlevsel ve örgütsel özellikleri bağlamında diğer örgüt türlerinden farklılaşma noktaları, bu açılardan sağlık kurumları yönetimine yaklaşmanın nasıl bir değer katabileceği teorik çerçevede incelenmiştir. $\mathrm{Bu}$ inceleme sonucunda, örgütü yapısal, kültürel ve fonksiyonel bakımdan farklı açılardan ele alan teori ve yaklaşımların, bazı sınırlılıklarına rağmen sağlık kurumları yönetiminde kullanımının faydalı olacağı sonucuna varılmıştır.

Sağlık kurumları, klinik ve yönetsel süreçlerin etkileşimi bağlamında ayrı konumlanmaktadır. $\mathrm{Bu}$ nedenle örgütsel yapının farklı boyutlarının yönetiminde çoklu yöneticilik becerilerinin önemi karşımıza çıkmaktadır. Temel yöneticilik yetkinliklerinin belirlenmesi ve uygulanması ile yönetimin zorlukları bertaraf edilip sağlı kurumları etkili yönetilebilecek ve sunulan sağlık hizmetinin sürdürülebilir olması sağlanabilecektir.

Hizmetten faydalanan hastaları ve talebe bağlı olarak ortaya çıkan sağlık hizmetini arz eden farklı meslekteki kamu sağlık personelini ve sağlık hizmeti sunum sürecinin tüm basamaklarını bilimsel yöntem ve tekniklere uygun, hizmeti sunan ve faydalanan tarafların bu süreçten maksimum memnuniyeti ile birlikte yönetebilmek, sağl1k sektörünü tanıyan herkesin yapabileceği bir iş, uğraş, faaliyet değildir. Özetle, sağlık hizmetleri ve hizmetin sunulduğu örgütler, sadece belirli bir meslek grubuna birakılamayacak kadar karmaşık yapıda olup sağlık hizmetlerinin yönetiminde, sağlık ekibinin üyesi olarak tüm mesleklerin söz sahibi olabilmesi ve/veya yönetici olarak sektöre özgü tüm yetkinliklere sahip kişilerin yönetim görevlerinde tercih edilmesi sayesinde sağlık kurumları etkin, etkili, ekonomik, kolay erişilebilir, kaliteli ve verimli faaliyet gösterebilecektir. Sağlı ekibinin tüm üyelerinin, disiplinler arası iş birliği içinde ve kurumlarının varoluş amaçlarını yerine getirmede uyum içinde çalışmaları teşvik edilmeli, öğrenimleri süresince bu konularda eğitim almaları sağlanmalı, bu bakımdan farkındalıkları ve motivasyonları artırılmalıdır. $\mathrm{Bu}$ bağlamda, sağlık meslek mensuplarının takım çalışması becerilerinin geliştirilmesine yönelik çalışmalara ihtiyaç bulunduğu açıktır.

\section{Kaynakça}

Akbulut, Y. (2015). Sağlık Okuryazarlığının Sağlık Harcamaları ve Sağlık Hizmetleri Kullanımı Açısından Değerlendirilmesi. İçinde: F. Yıldırım \& A. Keser (Ed.), Să̆lık Okuryazarliğl (s.113-132). Ankara Üniversitesi Basımevi.

Bannerman, R.H., Burton, J. \& Ch'en, W.C. (1983). Traditional Medicine and Health Care Coverage: A Reader for Health Administrators and Practitioners. Geneva: World Health Organization (WHO).

Bate, P. (2000). Changing the Culture of a Hospital: From Hierarchy to Networked Community. Public Administration, 78 (3), 485-512.

Bertalanffy, L.V. (1968). General System Theory: Foundations, Development, Applications. New York: George Braziller Publishers.

Camgöz-Akdağ, H., Tarım, M., Subash, L., \& Yatkın, A. (2013). QFD Application Using SERVQUAL for Private Hospitals: A Case Study. Leadership in Health Services, 26(3), 175-183.

Çakmak, M., Öktem, M.K. \& Ömürgönülşen, U. (2009). Türk Kamu Hastanelerinde Teknik Verimlilik Sorunu: Veri Zarflama Analizi Tekniği ile Sağlık Bakanlığı'na Bağlı Kadın Doğum Hastanelerinin Teknik Verimliliklerinin Ölçülmesi, Hacettepe Sağlık İdaresi Dergisi, 12(1), 1 36.

Çakmak, B.M. (2016). Să̆llk Bakanlı̆̆ Hastanelerinde Hekim Yöneticilerin Yönetsel Beceri ve Rollerinin Incelenmesi. Doktora Tezi, Ankara: Hacettepe Üniversitesi. 
Cronin, J.J., \& Taylor, A.S. (1992). Measuring Service Quality: A Reexamination and Extension. Journal of Marketing, 56(3), 55-68.

Cutler, D.M. \& McClellan, M. (2001). Is Technological Change in Medicine Worth it? Health Affairs, 20(5), 11-29.

Degeling, P., Maxwell, S., Kennedy, J., \& Coyle, B. (2003). Medicine, Management and Modernization: 'A Dance Macabre’. British Medical Journal, 326(7390), 649652.

Dickinson, H., \& Ham, C. (2008). Engaging Doctors in Leadership: Review of Literature. University of Birmingham NHS Institute for Innovation and Improvement Coventry.

Drucker P.F. (1980). Fırtınalı Dönemlerde Yönetim. Bülent Toksöz (Çev.). İstanbul: İnkılap Yayınevi.

Edmonstone, J. D. (1986). If You're Not the Woodcutter, What Are You Doing with That Axe?: Problems of Managing the NHS. Health Services Manpower Review, 12(3), 812.

Embertson, M.K. (2006). The Importance of Middle Managers in Healthcare Organizations. Journal of Healthcare Management/American College of Healthcare Executives, 51(4), 223-232.

Fişek, N.H. (1985). Halk Sağlı̆̆ına Giriş. Ankara: Hacettepe Üniversitesi Dünya Sağlık Örgütü Hizmet Araştırma ve Araştırıcı Yetiştirici Merkezi.

Fitzpatrick, R. \& Hopkins, A. (1983). Problems in the Conceptual Framework of Patient Satisfaction Research: An Empirical Exploration. Sociology of Health and Illness, 5(3), 297-311.

Folland, S., Goodman, A.C. \& Stano, M. (2007). The Economics of Health and Health Care. 7. Bask1. New Jersey: Pearson Education Inc.

Galbraith, J.K. (1967). The New Industrial State. Boston: Houghton Mifflin Company. (Erişim Tarihi: 20.09.2018),http://www.ebbemunk.dk/technostructure /technostructurep3.html

Gemlik, N., Manioğlu, Y., \& Çatar, Ö. (2015). Geert Hofstede'in Örgüt Kültürü Modeline Göre Sağlık Meslek Gruplarının Incelenmesi ve Kamu Özel Hastanelerinde Karşılaştırmalı Bir Araştırma. Hacettepe Üniversitesi Sağlık Bilimleri Fakültesi, Vol $1,1-14$.

Ginter, P.M., Duncan, W.J., \& Swayne, L.E. (2018). The Strategic Management of Health Care Organizations. Eight Edition, Hoboken, New Jersey: John Wiley \& Sons Inc.

Goes, J.B. \& Park, S.H. (1997). Interorganizational Links and Innovation: The Case of Hospital Services. Academy of Management Journal, 40(3), 673-696.

Jemal, H., Kechaou, Z., Ayed M.B., \& Alimi A.M. (2015). A Multi Agent System for Hospital Organization. International Journal of Machine Learning and Computing, 5(1), 51-56.
Kavuncubaș1, Ş. (2000). Hastane ve Sağlık Örgütleri Yönetimi, Ankara: Siyasal Yayınevi.

Kılıç, M., Arslan, M., Leblebici, D.N., Aydın, M.D., \& Öktem, M.K. (2008). Managerial Control vs Professional Autonomy: An Empirical Study on Perceptions of Physicians at Teaching Hospitals in Turkey, Journal of Medical Systems, 32(2), 157-165.

Kouzes, J.M., \& Mico, P.R. (1979). Domain Theory: An Introduction to Organizational Behavior in Human Service Organizations. Journal of Applied Behavioral Science October, 15 (4), 449-469.

Kuntz, L., \& Vera, A. (2007). Modular Organization and Hospital Performance. Health Services Management Research, 20, 48-58.

Kuntz, L., \& Vera, A. (2010). Transfer Pricing in Hospitals and Efficiency of Physicians: The Case of Anesthesia Services. İçinde: A. Vera (Ed.), Krankenhausmanagement in einem wettbewerbsorientierten Umfeld. Köln: Josef Eul Verlag GmbH.

Leggat, S.G. (2007). Effective Healthcare Teams Require Effective Team Members: Defining Teamwork Competencies. BMC Health Services Research, 7-17.

Leggat, S., Stanton, P., \& Bamber, G.J. (2018). New Development: 4P Recommendations for Implementing Change, From Research in Hospitals. Journal of Public Money \& Management, 38(1), 45-50.

Loh, E. (2013). How and Why Doctors Transition from Clinical Practice to Senior Hospital Management: A Case Research Study from Victory, Australia. International Journal of Clinical Leadership, 22(4), 235-244.

Medgadget (2017). University of Minnesota Researches Develop a Better 3D-Printed Organ Model. (Erișim: 07.12.2018),https://www.medgadget.com/2017/12/uni versity-minnesota-researchers-develop-better-3dprinted-organ-model.html

Mintzberg, H. (1980). Structure in 5's: A Synthesis of the Research on Organization Design. Management Science, 26(3), 322-341.

Mintzberg, H. (2002). Managing Care and Cure-up and down, in and out. Health Services Management Research, 15, 193-206.

Montgomery, K. (1990). A Prospective Look at the Specialty of Medical Management. Work and Occupation, 17, 178-198.

Olden, P.C. (2016). Contingency Management of Health Care Organizations: It Depends. The Health Care Manager, 35(1), 28-36.

Özcan, Y. (2013). Sağlık Kurumlarl Yönetiminde Sayısal Karar Yöntemlerine Giriş. Şahin Kavuncubaş1, Selami Yıldırım (Çev.). Ankara: Siyasal Kitabevi.

Parasuraman, A.P., Zeithaml, A.V., \& Berry L.L. (1988). SERVQUAL: A Multiple-item Scale for Measuring Consumer Perceptions of Service Quality. Journal of Retailing, 64(1), 12-40. 
Pillay, R. (2018). Healthcare 3.0 How Technology is Driving the Transition to Prosumers, Platforms and Outsurance. Xlibris Corp.

Pfeffer, J. (1973). Size, Composition, and Function of Hospital Boards of Directors: A Study of OrganizationEnvironment Linkage. Administrative Science Quarterly, 18(3), 349-364.

Raelin, J.A. (1999). Kültürlerin Çatışması YönetenlerYönetilenler. Kamuran Tuncay, Mürşit Balanlılar, Ahmet Buğdaycı (Çev.). İstanbul: Türkiye İş Bankası Kültür Yayınları.

Romero, L.M.R., Tosina, L.J.R., Valderrama, M.A.E., Arbizu, J.C., \& Martinez, I.R. (2011). A Comprehensive View of the Technologies Involved in Pervasive Care. İçinde: L. Bos, L.K. Carroll, A. Marsch \& L.M. Roa (Ed.), Future Visions on Biomedicine and Bioinformatics 1 (s.3-21). Berlin Heidelberg: Springer- Verlag.

Sağlık Bakanlığı (2018). Sağlık İstatistikleri Yıllı̆̆ 2017.

Santos, F.M. \& Eisenhardt, K.M. (2005). Organizational Boundaries and Theories of Organization. Organization Science, 16(5), 491-508.

Scott, R.W. (1982). Managing Professional Work: Three Models of Control for Health Organizations. Health Services Research, 17 3), 213-240.

Sen, A. (1999). Health in Development. Bulletin of the World Health Organization, 77(8), 619-623.

Swan, M. (2009). Emerging Patient-Driven Health Care Models: An Examination of Health Social Networks, Consumer Personalized Medicine and Quantifies SelfTracking. International Journal of Environmental Research and Public Health, 6, 492-525.

Şahin, B. (1999). Sağlıkta Yönetim Zorluğu Hekim Otonomisinin Sonu Olabilir mi? Hacettepe Sağllk Idaresi Dergisi, 4(1), 27-42.

Taner, T. \& Antony, J. (2006). Comparing Public and Private Hospital Care Service Quality in Turkey. Leadership in Health Services, 19(2), 1-10.

Thorne, M.L. (2002). Colonizing the New World of NHS Management: The Shifting Power of Professionals. Health Services Management Resources, 15(1), 14-26.

Unger, P., Macq, J., Bredo, F., \& Boelaert, M. (2000). Through Mintzberg's Glasses: A Fresh Look at the Organization of Ministries of Health. Bulletin of the World Health Organization, 78(8), 1005-1014.

Williams, J.M., Griffiths, A.J., Jones, D., \& Eaton, P.N. (1995). Energy Consumption in Large Acute Hospitals. Energy\&Environment, 6(2), 119-134.

World Health Organization (2011). Health Systems Strengthening Glossary. (Erişim: 01.09.2018), https://www.who.int/healthsystems/Glossary_January 2011.pdf

Zeckhauser, R., \& Sommers, B. (2013). Consumerism in Health Care: Challenges and Opportunities. Virtual Mentor, 15(11): 988-992. 

